\title{
O "LUGAR" DO LIBERALISMO NO BRASIL DO SÉCULO XIX
}

\author{
EL "LUGAR" DEL LIBERALISMO EN EL BRASIL DEL SIGLO XIX \\ THE “PLACE” OF LIBERALISM IN BRAZIL OF THE 19TH CENTURY
}

\author{
Lucas Flôres VASQUES ${ }^{1}$
}

RESUMO: O "lugar" do liberalismo no Brasil do século XIX é alvo de grandes debates na filosofia política (RICUPERO, 2007). Assim, temos como objetivo mapear esse debate e fornecer uma síntese dessas posições. Para isso, faremos, primeiro, um retorno ao contexto de surgimento do liberalismo na Inglaterra e, posteriormente, avançaremos para seus princípios filosóficos em John Locke. Em seguida, demonstraremos como esses princípios filosóficos foram interpretados no Brasil em três posições: primeiro como "ideia fora do lugar" (SCHWARZ, 2000; NOGUEIRA, 1976), segundo como "uma ideia tende a encontrar seu lugar" (COUTINHO, 2000) e terceiro como uma "ideia que está em seu devido lugar" (FRANCO, 1976; BOSI, 2010).

PALAVRAS-CHAVE: Liberalismo. Filosofia política. Liberdades. Século XIX.

RESUMEN: El "lugar" del liberalismo en el Brasil del siglo XIX es objeto de grandes debates en filosofía politica (RICUPERO, 2007). Por lo tanto, nuestro objetivo es trazar un mapa de este debate y ofrecer una sintesis de estas posiciones. Para ello, primero haremos un retorno al contexto de la irrupción del liberalismo en Inglaterra y, posteriormente, avanzaremos a sus principios filosóficos en John Locke. Luego, demostraremos cómo estos principios filosóficos fueron interpretados en Brasil en tres posiciones: primero como "idea fuera de lugar" (SCHWARZ, 2000; NOGUEIRA, 1976), segundo como "una idea tiende a encontrar su lugar" (COUTINHO, 2000) y tercero como una "idea que está en su debido lugar" (FRANCO, 1976; BOSI, 2010).

PALABRAS CLAVE: Liberalismo. Filosofía política. Libertades. Siglo XIX.

ABSTRACT: The "place" of liberalism in Brazil of the 19th century had been the subject of major debates in the Social Sciences. Thus, we aim to map this debate and provide a summary of these positions. To do this, we will first make a return to the context of the emergence of liberalism in England, then we will advance to its philosophical principles in John Locke. Then, we will demonstrate how these philosophical principles were interpreted in Brazil in three positions: First as an "idea out of place" (SCHWARZ, 2000; NOGUEIRA, 1976), second as "an idea tends to find its place" (COUTINHO, 2000) and third as an "idea that is in its right place" (FRANCO, 1976; BOSI, 2010).

KEYWORDS: Liberalism. Political philosophy. Freedom. 19th century.

${ }^{1}$ Universidade Estadual Paulista (UNESP), Araraquara - SP - Brasil. Mestrando no Programa de Pós-Graduação em Ciências Sociais. ORCID: https://orcid.org/0000-0003-1124-8506. E-mail: lucas.vasques@unesp.br 


\section{Introdução}

Segundo Raymundo Faoro (1987), o pensamento político não pode ser resumido à filosofia política, ciência política ou ideologia. O pensamento político, assim, é dotado de uma existência própria, autônoma. Desse modo, reduzir o pensamento político a uma mera filosofia política leva a uma desfiguração da própria história, bem como a um descolamento da realidade. As filosofias políticas, tal como o liberalismo, representam uma ferramenta teleológica, um objetivo abstrato a ser perseguido. Já o pensamento político é a sua materialização. Faoro (1987, p. 15) afirma que "O pensamento político está dentro da experiência política, incorporado à ação, fixando-se em muitas abreviaturas, em corpos teóricos, instituições e leis".

O objetivo do presente artigo o objetivo do presente artigo é compreender como o debate em torno da filosofia política do liberalismo inglês se estrutura enquanto pensamento político no Brasil no século XIX ${ }^{2}$. Para esse objetivo, o presente artigo é composto por duas partes. $\mathrm{Na}$ primeira parte faremos um retorno para entender o contexto de formação do liberalismo inglês. Superada essa questão, avançaremos para a compreensão dos princípios da filosofia política liberal através dos escritos de John Locke (1994). Introduzido seu contexto e princípios, verificaremos como a filosofia política liberal no Brasil é interpretada e debatida.

Com esse objetivo, o texto mais conhecido e amplamente referenciado, é o de Bernardo Ricupero (2007), intitulado Da formação à forma: Ainda as "idéias fora do lugar". Todavia, tal texto não é capaz de fornecer um panorama geral dos debates acerca do tema ao excluir a posição de Marco Aurélio Nogueira (1976) acerca do tema. Além disso, o texto de Ricupero (2007) divide as posições acerca do tema em dois eixos opostos: "As ideias fora do lugar" (SCHWARZ, 2000) e “As ideias estão no seu devido lugar" (BOSI, 2010; COUTINHO, 2000; FRANCO, 1976), simplificando a posição adotada por Carlos Nelson Coutinho (2000). Como demonstraremos a seguir, a posição de Coutinho (2000) nesse debate não deve ser simplificada no chavão “As ideias estão em seu lugar” sob risco de essencializar

\footnotetext{
2 Tratamos do liberalismo inglês apenas como uma forma de recorte teórico e empírico. Afinal, se considerarmos o liberalismo em sua versão francesa, o liberalismo doutrinário, os termos de debate se complexificam. Afinal, se considerarmos a atuação de pensadores como José Bonifácio de Andrada e Silva, verificaremos que sua trajetória filosófica e política fora marcada pela contestação da escravidão. Escravidão essa, que fora argumento de contestação do "lugar" do liberalismo no século XIX, como veremos à frente. José Bonifácio de Andrada e Silva teve suas ideias liberais sempre em atrito com a sociedade brasileira escravocrata e senhorial. Profundamente influenciado pelas teses de John Locke, empenhou-se na abolição gradual da escravidão na expansão do ensino básico e secundário e defendeu, também, a expansão do país para o interior do continente. Propôs a integração do índio à sociedade civil, também com a miscigenação como um fato de integração e de identidade nacional. Este intelectual se consagra como grande inspirador da busca por uma identidade nacional, inspirando debates até três séculos depois de escrever suas teses. Defensor do Estado centralizado, influenciou a independência do Brasil.
} 
a discussão e passar a falsa impressão de que se trata de uma discussão linear, composta apenas de duas posições binárias.

Para constituir uma leitura sistemática dessa discussão, destacamos que não existem apenas duas posições binárias no debate, mas na realidade três vertentes que marcam posições diferentes sobre o liberalismo no Brasil: 1) "As ideias fora do lugar" (SCHWARZ, 2000; NOGUEIRA, 1976); 2) “As ideias tendem a encontrar seu lugar" (COUTINHO, 2000) e 3) “As ideias estão em seu devido lugar" (FRANCO, 1976; BOSI, 2010). Com intuito de compreender como se constitui essa problemática, avançaremos primeiro ao contexto de construção do liberalismo.

\section{O contexto de surgimento do liberalismo}

O contexto de surgimento do pensamento liberal remete ao século XVII nas disputas dos absolutistas com a burguesia ascendente. Soma-se a essa disputa, católicos, anglicanos, presbiterianos e puritanos também lutavam pela hegemonia religiosa na Inglaterra. Esse quadro político e social culminaria em 1640 em um conflito armado entre as forças militares do rei Carlos I e o parlamento inglês. Denominada de Revolução Puritana, a batalha terminou com a vitória dos parlamentaristas e a execução de Carlos I.

Assim, após um regicídio, instaurou-se o governo republicano de Oliver Cromwell (1599-1658), cujos excessos e opressões embasaram Thomas Hobbes (1588-1679) na escrita, em 1651, de O Leviatã. A ditadura de Oliver Cromwell (1599-1658) prosperou militarmente e comercialmente até sua morte em 1958. Como seu sucessor, seu filho Richard Cromwell não teve o mesmo sucesso, sendo deposto com apenas 18 meses de governo. Sua deposição mergulhou a Inglaterra novamente em uma crise política e social que terminaria em uma guerra civil, cujo resultado foi o retorno da monarquia Stuart ao poder. Nesse período, ocorreu o retorno das tensões entre Coroa e Parlamento, na medida em que o último era contrário as tomadas de posição pró-católica dos absolutistas Stuart.

O retorno da monarquia ao poder só aconteceu com a coroação de Carlos II (16301685), que aceitou a prerrogativa dos parlamentaristas de ter seus poderes reduzidos. Todavia, por adotar posições favoráveis a liberdade religiosa, o rei entrou em choque com o parlamento, levando a dissolução do último em 1681. O reinado de Carlos II durou até sua morte, em 1685, quando pela ausência de um herdeiro, foi sucedido por seu irmão, Jaime II (1633-1701). 
A exemplo de seu irmão, Jaime II demonstrava inclinações pelo exercício pleno do absolutismo. Essas inclinações de Jaime, levaria a uma união de políticos ingleses, dos mais diversos espectros políticos, como uma forma de retirá-lo do poder. Com a intenção de concretizar esse plano, políticos ingleses conspiram com Guilherme III (1650-1702), príncipe de Orange. Em 1688 o parlamento coroa Guilherme como rei da Inglaterra, sem derramamento de sangue, após a fuga de Jaime II para França. Sobre a alcunha de Revolução Gloriosa, esse período histórico demarcava o triunfo de um conjunto de ideias e práticas políticas que receberiam o nome de liberalismo, através de seu maior expoente, John Locke (1632-1704).

\section{John Locke, o fundador do liberalismo}

John Locke (1632-1704), opositor da monarquia Stuart, é exilado e retorna a Inglaterra somente com a concretização da Revolução Gloriosa. Nesse interim, foi publicado O segundo tratado (LOCKE, 1994) como justificação e legitimação da Revolução Gloriosa. A base dessa defesa foi o direito à resistência, em que o povo poderia resistir ao soberano caso julgasse necessário. Seu retorno para Inglaterra ocorre sobre o clamor e reconhecimento do rei Guilherme de Orange (WEFFORT, 2001).

Para compreender o liberalismo para além de seu contexto histórico, faremos uma incursão através de suas principais concepções filosóficas: lei natural, estado de natureza, propriedade privada, dinheiro, estado de guerra, contrato, sociedade política e governo (VARNAGY, 2006). A concepção de John Locke de lei natural consiste na crença de que certas leis da natureza também governam e que podem ser desvendadas com o uso da razão. Com isso, para o autor existiria uma racionalidade inscrita no coração dos homens. Tal racionalidade, seria inculcada nos homens através das ações próprias de um Deus, na medida em que cumpririam o propósito do discernimento entre o bem e o mal, enquanto um instinto de preservação da própria vida, liberdade e propriedade, direitos irrenunciáveis (LOCKE, 1994).

Embora a lei natural é constituída por um imperativo político que não cessa com a formação da sociedade. Pelo contrário, na perspectiva de Locke (1994), tornar-se-á mais rigorosa pela ação do direito e das leis. Assim, as leis naturais seriam dotadas de um poder coercitivo para com aqueles que a infringem.

Já o estado de natureza no liberalismo de John Locke é um imperativo filosófico para se pensar o estado natural dos seres humanos. Assim, para Locke (1994), os seres humanos, 
enquanto uma criação divina, viveriam em um estado primeiro de perfeita igualdade e liberdade natural. Nesse estado, toda subordinação e vassalagem não existiria, sendo os seres humanos submetidos apenas a força das leis naturais, sem a existência do direito.

Outro princípio importante do liberalismo é a noção de propriedade privada. Segundo Varnagy (2006, p. 60), a noção de propriedade privada em Locke é polissêmica: “[...] em sentido amplo e geral, implica "vida, liberdade e terra" (II, 87, 123, 173) e, num sentido mais estrito, bens, o direito à herança, e a capacidade de acumular riquezas". Para tanto, a propriedade em Locke (1994) não é ilimitada, pois para ele a posse depende intimamente da quantidade de trabalho depositada no objeto ou local. Assim, o autor (LOCKE, 1994) vincula o trabalho ao valor de determinado objeto. Quanto mais trabalho é realizado - este limitado pelas capacidades individuais - maior o é valor do produto.

Na questão do dinheiro, Locke (1994) argumenta que graças à sua criação, os homens conseguiram criar além de sua própria subsistência. Assim, os homens conseguiram acumular suas posses e seu próprio excedente. Para isso, o dinheiro torna-se um instrumento durável que o homem poderia guardar sem o risco temporal de seu apodrecimento, tal como os alimentos produzidos em suas terras. Isso se deve, também, ao pacto aceito tacitamente que garantiu ao dinheiro esse status.

Como consequência desse processo, houve um acúmulo e concentração de bens e terras. Na medida em que a sociedade comercial se complexifica, começam a existir conflitos pela posse de bens que resultará no fim do estado de natureza. Como resultado desse processo, fara-se necessário a construção do direito, das leis e do próprio Estado, como um meio de regulação de conflitos. Desse modo, o Estado em Locke (1994), além de garantir a posse de propriedade, deve ser responsável pela penalização dos indivíduos que transgridam as leis. Desse modo, Tomas Varnagy (2006) propõe uma divisão do estado de natureza de John Locke em duas etapas: a primeira, referente a propriedade limitada, baseada no trabalho e a segunda, da propriedade ilimitada, mediada pela existência do dinheiro:

É possível então estabelecer períodos referentes ao estado de natureza, no qual há sociedade e reina a lei natural, em duas etapas: na primeira, a propriedade é limitada pelo trabalho e a vida é agradável e aprazível; na segunda, que surge com o aparecimento do dinheiro, dá-se tanto a possibilidade de acumulação ilimitada quanto a desigualdade em relação às posses (VARNAGY, 2006, p. 63).

Apesar desse estado de natureza pacífico e harmonioso, surge a necessidade de homens se organizarem em sociedade. Assim, com os problemas decorrentes do surgimento 
do dinheiro, os homens se organizam em um governo civil como uma forma de proteção mútua, com a segurança de suas vidas, bens e propriedades.

Em síntese, o propósito principal da sociedade política é proteger os direitos de propriedade em sentido amplo, ou seja, a vida, a liberdade e os bens. Como esses direitos existem antes da constituição da sociedade e inclusive na própria sociedade política, não pode haver nenhum direito a impor, por exemplo, impostos sem o consentimento de seus membros (VARNAGY, 2006, p. 68).

Como consequência, segundo Locke (1994), os homens entram em um governo civil para se protegerem e protegerem seus bens. Todavia, sempre que um legislador ou governante se voltar contra os interesses dos homens e violar suas propriedades, o povo teria o chamado "direito de resistência". Na medida em que se esvazia a confiança no legislador, os cidadãos poderiam, em comum acordo, dissolver sua autoridade.

Somados todos esses princípios, como sintetizar o liberalismo? Thomas Varnagy (2006) afirma que essa seria uma tarefa extremamente árdua. Todavia, em um sentido amplo, liberalismo significa enfatizar as liberdades individuais frente às sanções externas. Assim, ser liberal, em sentido amplo na filosofia política, significa enfrentar todas as formas que buscam retirar dos indivíduos suas liberdades.

Como definir o liberalismo? (...). Num sentido amplo, enfatiza a liberdade do indivíduo diante das restrições externas (Igreja, Estado, tradições, sociedade). Nos séculos XVIII e XIX, baseava-se na idéia do livre mercado e procurava limitar os poderes do governo através de mecanismos tais como o federalismo e a separação de poderes, embora não implicasse necessariamente a democracia (VARNAGY, 2006, p. 77).

A despeito dessa dificuldade em se definir o termo "liberalismo", essa filosofia política acabou por ser lida no Brasil sobre três eixos de interpretação, no primeiro como uma "ideia fora do lugar" (NOGUEIRA, 1976; SCHWARZ, 2000), segundo como uma "ideia que tende a encontrar seu lugar" (COUTINHO, 2000) e, por fim, como uma "ideia que está em seu devido lugar" (BOSI, 2010; FRANCO, 1976).

\section{As ideias fora do lugar}

Roberto Schwarz, em sua tese sobre "as ideias fora do lugar", na obra Ao Vencedor as Batatas (2000), busca demonstrar quais são as relações entre o liberalismo, filosofia, e seu pensamento político no Brasil. Nela, Schwarz demonstra que há uma lacuna entre teoria e prática no Brasil. Essa lacuna é mediada pela prática do favor. Através da prática do favor, 
toda a estrutura social, política e econômica essencializa-se na figura das elites locais. Assim, a prática política torna-se um instrumento de defesa e perpetuação de interesses pessoais.

O substrato dessa prática política, segundo Schwarz, foi a filosofia liberal. Ao lado do liberalismo, o romance, o sistema parlamentar e as normais jurídicas foram "emprestados de países centrais como forma de "civilizar-se" (RICUPERO, 2008). Ou seja, foram ideias retiradas de seu local de origem, países centrais, e utilizadas em países periféricos, distante de suas condições sociais de produção. Isso resultou em um processo de descolamento de suas práticas primeiras:

Schwarz indica, em outras palavras, que países periféricos, como o Brasil, teriam que tomar emprestado de países centrais formas, como o romance, o sistema parlamentar, as normas jurídicas e tudo mais que os tornassem "civilizados" (Arantes, 1992; Palti, 2007). No entanto, suas condições sociais teriam pouco em comum com as que produziram originalmente essas formas, o que faria com que sofressem "torção", tornando-se praticamente irreconhecíveis (RICUPERO, 2008, p. 64-65).

Assim, segundo Schwarz (2012), a ideologia liberal assume seu posto de "ideia fora do lugar" em sua prática política no Brasil. Apesar de impulsionar a libertação das colônias em toda América, o liberalismo no Brasil serviu, paradoxalmente, para preservar o legado da escravidão e do monopólio da terra nas mãos dos latifundiários. Afinal, no Brasil, em meados do século XIX, o trabalho escravo e, em especial, o tráfico negreiro, prosperaram como uma forma de organização social. Destaca-se, sobre inspiração liberal, o processo de independência brasileira à metrópole portuguesa. Para Vivaldo Daglione (1961), o liberalismo no Brasil Império tomou para si roupagens aristocráticas, onde travou-se uma batalha política com a burguesia mercantil. Esse processo culminou em 1823 com a constituinte, sob a promessa de uma "nova constituição duplamente liberal".

Schwarz (2000) coloca que a ideologia liberal serviu na Europa como uma forma de encobrir a exploração do trabalho sobre as ideias de liberdade de trabalho e igualdade jurídica. Todavia, no Brasil, essa exploração era mais explícita, calcada na escravidão e no tráfico negreiro. Um dos maiores exemplos disso foi a constituição de 1824 que, apesar de se colocar como uma constituição liberal, mantinha a escravidão. Desse modo, o autor argumenta que a predominância do pensamento liberal no comércio internacional ecoou no Brasil, fazendo sua burguesia se assentar sob um raciocínio econômico que visa o lucro. Somado a isso, segundo o autor (SCHWARZ, 2000) a independência brasileira também fora baseada em ideais liberais. Toda essa conjuntura acabou se chocando com o modo de produção escravagista e, 
em especial, aos proprietários de escravizados, os latifundiários e a elite agrária (SCHWARZ, 2000).

Essa relação ambígua ou arlequinal entre liberalismo e prática política serviu para produzir três classes: o latifundiário, o escravizado e o homem livre. Sendo o último inteiramente dependente dos gestos do primeiro. Afinal, se a relação entre latifundiário e escravizado era mediada pela noção de propriedade, do latifundiário e do homem livre era o "favor". Portanto, o "favor" prevalece como uma mediação que assegura às suas partes a não escravização.

[...] o favor assegurava às duas partes, em especial à mais fraca, de que nenhuma é escrava. Mesmo o mais miserável dos favorecidos via reconhecida nele, no favor, a sua livre pessoa, o que transformava prestação e contraprestação, por modestas que fossem, numa cerimônia de superioridade social, valiosas em si mesma (SCHWARZ, 2000, p. 8).

O "favor" coloca-se enquanto um mecanismo de reprodução das classes dos homens livres e dos proprietários. Uma mediação relacional cuja explicitação na dependência da pessoa e na remuneração de serviços pessoais. Para tanto, as classes incompatíveis, ou melhor, produtivamente antagônicas, de proprietários e homens livres, acordam tacitamente em cooperar para benefício mútuo. Essa cooperação vem para assegurar para ambas as partes que nenhuma delas é escrava e, portanto, privada de suas liberdades. Para Scharwz (2000), até mesmo o "mais miserável dos favorecidos" vê no favor o reconhecimento de suas liberdades, de sua pessoa.

Outro cientista a considerar o liberalismo como "ideia fora do lugar" fora Marco Aurélio Nogueira (1976), estudando a figura histórica de Joaquim Nabuco. Nesse estudo, defende que liberalismo no Brasil sempre foi muito vazio de inspirações igualitárias. Dessa forma, ainda segundo Nogueira, o liberalismo no Brasil é mais uma liberdade de nação do que uma liberdade do indivíduo. O liberalismo, portanto, assume-se como uma prática política contraditória, que não foi capaz de encontrar na colônia, bases sociais, políticas e econômicas para sua plena realização.

\section{As ideias tendem a encontrar seu lugar}

Já Carlos Nelson Coutinho assume uma posição intermediária no debate. Para ele, o liberalismo em dado momento fora uma ideia fora do lugar no Brasil, porém com o processo de modernização capitalista, ele tenderia a "encontrar seu lugar". Para compreender essa posição, devemos fazer um retorno teórico a sua obra Cultura e Sociedade no Brasil (2000), 
que destaca a existência de um intimismo à sombra do poder no Brasil. Tal ideia, postulada por Georg Lukács (1972), demonstra a existência de uma forte atração entre os intelectuais e o Estado, tendo o Estado como promotor das transformações sociais. Dessa forma, Lukács (1972) identifica uma revolução conservadora, feita de cima para baixo, sem a participação popular e com forte atração ao autoritarismo, caracterizando uma modernização por "via prussiana" 3 " ou de caráter "intimista".

[...] as transformações ocorridas em nossa história não resultaram de autênticas revoluções, de movimentos provenientes de baixo para cima, envolvendo o conjunto da população, mas se processaram sempre através de uma conciliação entre os representantes dos grupos opositores economicamente dominantes, conciliação que se expressa sob a figura política de reformas "pelo alto" (COUTINHO, 2000, p. 50).

Ao operacionalizar tal conceito, utilizando também a noção de "revolução passiva" de Gramsci, Coutinho faz uma análise do "lugar das ideias" no Brasil e, em especial, do papel dos intelectuais nesse processo. Aponta que as revoluções modernizadoras no Brasil assumiram um caráter passivo em que os intelectuais foram cooptados para realizá-las. Desse modo, através da conciliação entre frações das classes dominantes, com a conservação do latifúndio e a manutenção da dependência ao capital internacional, as camadas populares se viram excluídas das decisões políticas tomadas no Brasil, através de um processo denominado "revolução passiva" (COUTINHO, 1980).

Em suma, Coutinho (1980) demonstra que existe no Brasil um cooptação dos intelectuais pela elite para construção de uma revolução passiva. Para tanto, os intelectuais se colocaram de forma "íntima ao poder" das elites e do Estado. Na medida em que esse processo "intimista" avança, a modernização capitalista, impulsionando e sendo impulsionada por um desenvolvimento prussiano, acaba por colocar as ideias no seu "devido lugar". Ou seja, na medida em que o processo de cooptação dos intelectuais e do desenvolvimento capitalista avança, a sociedade vai se tornando mais aderente às realidades e aos interesses de classe que tentam expressar.

Para Coutinho, conquanto o processo de modernização avança, mais parecida a sociedade brasileira fica à sociedade capitalista geral, tendo maior sensibilidade às ideias lá formuladas e aqui importadas. Portanto, seguindo a perspectiva do autor, o liberalismo tende a

${ }^{3} \mathrm{O}$ conceito de "via prussiana" fora formulado por Lenin e utilizado tanto por Lukács e Coutinho, expressa, para Vladmir Lenin, o processo de modernização "pelo alto" ocorrido na Alemanha, Itália e o Japão. Para conhecer mais sobre o assunto ler Cultura e Sociedade no Brasil, capítulo II, de Carlos Nelson Coutinho, publicado em 2000 pela editora DP\&A. 
se tornar uma "ideia no lugar" no Brasil na medida em que o processo intimista de modernização capitalista avança.

Diferentemente da posição a seguir, adotada por Franco (1976) e Bosi (2010), Coutinho (1980) coloca uma dimensão temporal e processual na questão do liberalismo como ideia "em seu lugar”. Entretanto, enquanto Franco (1976) e Bosi (2010) colocam o liberalismo como uma ideia "fixa" que independe do tempo e "lugar", Coutinho (1980) demonstra as relações "intimas" entre a ideia de liberalismo e o processo de modernização das elites brasileiras, bem como o papel central dos intelectuais nesse processo. Na medida em que esse processo avança, o liberalismo "tende a encontrar seu devido lugar" no desenvolvimento do capitalismo.

\section{As ideias estão em seu devido lugar}

Maria Sylvia de Carvalho Franco, partindo de uma perspectiva marxista em seu artigo As idéias estão em seu lugar (1976), defende que tanto em países de periferia quanto centro fazem parte da mesma ordem, ou seja, do mesmo sistema de produção, que tem por objetivo primordial, gerar lucro, ou seja, extrair a mais-valia do trabalho. Todavia, Carvalho Franco afirma que o liberalismo é o mesmo, tanto no Brasil quanto na Europa, adequando-se a uma lógica mundial de acumulação de capital. A integração do Brasil em uma lógica mundial, segundo a autora, nada tem de um liberalismo enquanto "ideia fora do lugar".

A exemplo de Carvalho Franco, Alfredo Bosi na obra Ideologia e Contra ideologia (2010), aponta que o liberalismo nunca foi "uma ideia fora do lugar" tanto no Brasil, como em qualquer outro país, seja periférico ou não. Sua análise parte do pressuposto de que na primeira metade do século XIX, a ideologia liberal foi hegemônica em todo Ocidente, explorando tanto o trabalhador das colônias (escravizado) ou das metrópoles. Ou seja, para o autor, o capitalismo explorou a mais-valia do trabalho em suas mais diversas expressões nesses lugares. Seja em ritmo ou local diferentes, "Velho Continente" ou "Novo Mundo", experimentaram a exploração capitalista impulsionada pelo liberalismo.

\section{Considerações finais}

Finalmente, nosso percurso metodológico consistiu em visitar o contexto histórico de emergência da filosofia liberal na Inglaterra. Nele, entendemos como em um momento na Inglaterra, em um contexto específico, a exaltação e a defesa das liberdades individuais 
resultaram em um processo de constituição de uma filosofia política que permanece como uma construção teleológica buscada pelas mais diversas democracias republicanas espalhadas pelo mundo.

Com a tomada do poder por Guilherme de Orange, o pensador político John Locke pôde retornar a Inglaterra após exílio na Holanda. Com isso, conseguiu concluir a redação de suas obras que serviriam de apoio à interpretação do liberalismo. Em um movimento de exaltação de defesa das liberdades individuais, do respeito à pessoa e a propriedade, o liberalismo enquanto uma filosofia política se espalhou por uma gama variada de países no século XIX, chegando até mesmo nos países periféricos, como o Brasil.

Essa chegada no Brasil é interpretada das mais diversas formas, seja como uma "ideia fora do lugar" (NOGUEIRA, 1976; SCHWARZ, 2000) ou "uma ideia que tende a encontrar seu lugar" (COUTINHO, 2000) e até mesmo como "uma ideia que está em seu devido lugar" (BOSI, 2010; FRANCO, 1976). Tal polêmica, destrinchada anteriormente nesse artigo, movimentou o cenário intelectual brasileiro nas últimas décadas. $\mathrm{O}$ fato é que tais visões se distinguem em três eixos teóricos, aqueles tais como Roberto Schwarz (2000) e Marco Aurélio Nogueira (1976), que consideram o liberalismo enquanto uma filosofia política inglesa $(\log o s)$ que não encontrou no Brasil as mesmas condições sociais para realizar-se tal como encontrou na Inglaterra. Assim, sua praxis fora arlequinal e incompleta, fazendo uso apenas de aspectos convenientes às elites.

O segundo eixo teórico de interpretação é baseado em Maria Sylvia de Carvalho Franco e Alfredo Bosi, segundo qual consideram o liberalismo apenas em prática política. Ou seja, independente do seu local original e condições específicas de produção, ele seria o mesmo em sua prática (praxis). Afinal, todos integramos o mesmo modelo de produção, o capitalismo.

A terceira via, representada por Carlos Nelson Coutinho, trabalha em um meio termo, oscila na compreensão do liberalismo entre as duas perspectivas anteriores. Considera que o liberalismo, apesar de estar descolado de seu contexto primeiro inglês, tenderia a colocar-se no Brasil, na medida em que se desenvolve, como uma "ideia no lugar".

Compreendendo esses três eixos de interpretação, como nos propomos, através da análise de Raymundo Faoro (1987) sobre o pensamento político, entendemos o liberalismo como um logos capaz de fornecer orientação teleológicas para a prática (praxis) do pensamento político. Assim, o liberalismo seria um sistema nomoempírico de filosofia política, surgido na Inglaterra através da prática (praxis) política da sociedade inglesa, imersa em contexto político, cultural e econômico específicos. Afinal, se na Inglaterra, a praxis política precedeu o exercício filosófico de sistematização escrita, no Brasil o logos fora 
enviado de uma forma que serviu, através da prática do favor e da escravização, como instrumento de concentração de poder político e econômico nas mãos das elites.

A segunda via teórica, expressa por Maria Sylvia de Carvalho Franco e Alfredo Bosi, apesar de fornecerem uma interpretação macroestrutural do sistema capitalista, coloca o liberalismo como o mesmo produto em termos de filosofia política (logos) e prática política (praxis). Assim, essencializa-se a filosofia política como subproduto do pensamento político (práxis) de outro contexto histórico (brasileiro século XIX), político e econômico, em detrimento daquele expresso na Inglaterra do século XVIII.

Roberto Schwarz (2012) também respondeu às considerações realizadas pelo Franco e Bosi sobre sua teoria das "ideias fora do lugar". Para o autor, seus críticos acabaram por se embasar em dicotomias inexistentes em suas obras, como se por objetivar que o liberalismo se formou enquanto uma filosofia política, estivesse negligenciando sua praxis no Brasil. Ainda assim, Schwarz (idem) afirma que as ideias podem sim ainda estarem "fora do lugar", mesmo servindo ao propósito da exploração capitalista, enquadrada numa lógica global do sistema de produção capitalista.

Em suma, esse artigo contribui com a discussão acerca do debate do "lugar" das ideias liberais no Brasil na medida em que se distancia da sistematização proposta por Bernardo Ricupero (2007) sobre uma primeira posição intitulada As ideias fora do lugar (SCHWARZ, 2000) e sua crítica As ideias estão no seu devido lugar (BOSI, 2010; COUTINHO, 2000; FRANCO, 1976). Na tentativa de superar essa visão dicotômica do debate, sistematizamos o "lugar" do liberalismo no Brasil em três posições distintas, das quais a primeira posição seria “As ideias fora do lugar" (NOGUEIRA, 1976; SCHWARZ, 2000), a segunda em que "As ideias tendem a encontrar seu lugar" (COUTINHO, 2000) e, por fim, "as ideias estão em seu devido lugar" (BOSI, 2010; FRANCO, 1976).

AGRADECIMENTOS: Agradeço à FAPESP (Fundação de Amparo à Pesquisa do Estado de São Paulo) pelo apoio.

\section{REFERÊNCIAS}

BOSI, A. O Pano de Fundo Ideológico: O liberalismo excludente. In: Ideologia e contraideologia: temas e variações. São Paulo: Companhia das Letras, 2010.

CARVAlHO, M. As ideias estão no lugar. Cadernos de Debate, v. 1, p. 61-64, 1976. 
COUTINHO, C. Cultura e Sociedade no Brasil: ensaio sobre idéias e formas. Rio de Janeiro: DP\&A, 2000.

COUTINHO, C. N. A democracia como valor universal: notas sobre a questão democrática no Brasil. São Paulo: Livraria Editora Ciências Humanas, 1980.

DAGLIONE, V. A evolução política-econômica das Américas: do liberalismo como movimento de libertação política nacional ao mercantilismo como movimento de afirmação econômico-nacional. Revista de História, v. 23, n. 46, 1961.

FAORO, R. Existe um pensamento político brasileiro? Estudos Avançados, São Paulo, v. 1, n. 1, p. 9-58, 1987.

LOCKE, J. Segundo tratado sobre o governo civil: ensaio sobre a origem, os limites e os fins verdadeiros do governo civil. Petrópolis, RJ: Vozes, 1994.

LUKÁCS, G. EI Asalto a la razón: la trayectoria del irracionalismo desde Schelling hasta Hitler. Barcelona-México: Ediciones Grijalbo, 1972.

NOGUEIRA, M. As desventuras do liberalismo: Joaquim Nabuco, a Monarquia e a República. Rio de Janeiro: Paz e terra, 1984.

NOGUEIRA, M. Socialismo e democracia no marxismo de Carlos Nelson Coutinho. Lua Nova, São Paulo, n. 88, 2013

RICUPERO, B. Da formação à forma: ainda as "ideias fora do lugar". Lua Nova, São Paulo, n. 73, p. 59-69, 2008.

SCHWARZ, R. Ao vencedor as batatas. São Paulo: Livraria Duas Cidades, 2000.

SCHWARZ, R. Martinha versus Lucrécia: ensaios e entrevistas. São Paulo: Companhia das Letras, 2012.

VARNAGHY, T. O pensamento político de John Locke e o surgimento do liberalismo. Buenos Aires; São Paulo: CLACSO/USP, 2006.

WEFFORT, F. Os clássicos da política. São Paulo: Editora Ática, 2001. 


\section{Como referenciar este artigo}

VASQUES, L. F. O "lugar" do liberalismo no Brasil do século XIX. Rev. Sem Aspas, Araraquara, v. 10, e021010, jan./dez. 2021. e-ISSN 2358-4238. DOI: https://doi.org/10.29373/sas.v10i00.15186

Submetido em: 09/05/2021

Aprovado em: 07/06/2021

Publicado em: 30/06/2021 